\title{
EcSocial.com \\ Servicio de información para la economía social
}

\author{
Por Antonia Ferrer
}

Resumen: Se aborda cómo se ha elaborado el Portal de Información de Economía Social de la Comunidad Valenciana (www.ecsocial.com). Se exponen sus orígenes, planificación, desarrollo, así como la metodología seguida para conseguir la participación de las empresas que pertenecen a este entorno. El documento plantea las variaciones que se han producido en el proyecto a lo largo de su evolución, así como el presupuesto que ha hecho posible que esta iniciativa se haya puesto en marcha.

Palabras clave: Economía social, Portales, Pyme, Pequeña y mediana empresa, Microempresas, Cooperativas, Servicios, Información para compañías, Tecnologías de la información para empresas, Directorios.

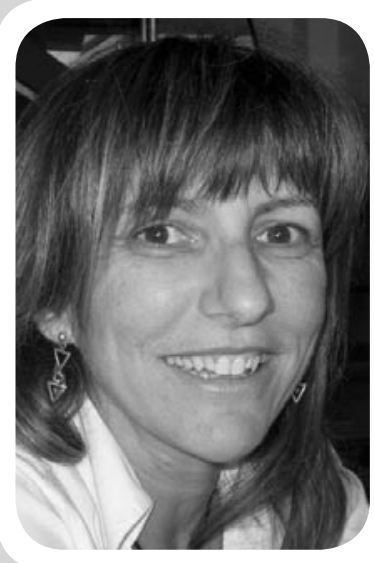

Antonia Ferrer Sapena, licenciada en geografía e historia en la especialidad de historia contemporánea, por la Universitat de Valencia (1981) y doctora en técnicas y métodos actuales en información y documentación en 2004. Coordinadora de investigación en Florida Centre de Formació y actualmente profesora de la Universidad Politécnica de Valencia. De los últimos proyectos dirigidos, cabe destacar el portal de Economía Social EcSocial.com http://www.ecsocial.com

\section{Title: EcSocial.com. Information service for the social economy}

Abstract: The origins, planning, and implementation process for the Valencian Community Social Economy Information Portal (www.ecsocial.com) are described. Details are provided of the methodology used to encourage participation by companies in this business realm. Changes that have taken place during the life of the project are detailed, along with the budget that has made this initiative possible.

Keywords: Social economy, Portals, SME, Small and medium size enterprises, Services, Information for companies, Information technologies for companies, Directories.

Ferrer, Antonia. "EcSocial.com. Servicio de información para la economía social". En: El profesional de la información, 2007, mayo-junio, v. 16, n. 3, pp. 225-234.

DOI: 10.3145/epi.2007.may.07

\section{Introducción}

LA ALFABETIZACIÓN DIGITAL EN ESPAÑA continúa siendo un reto. Muestra de ello es que ocupa el lugar 29 en el Global Information Technology Report 2004-2005', publicado por el World Economic Forum. Esta situación no es acorde con la capacidad competitiva de su economía, porque este informe la sitúa detrás de países como Estonia o Malta.

El escenario no ha mejorado: el informe 2005-2006 indica que España ha descendido dos posiciones, ocupando el lugar 31 del ranking 2 . Por ello, son necesarias más acciones por parte de las distintas administraciones de nuestro país para implantar las TIC en las empresas, especialmente en las microempresas y pymes.

A nivel estatal destacamos las de los ministerios de Industria, Educación, Turismo, etc., y también citaríamos varios gobiernos autonómicos.

En la Comunidad Valenciana las acciones más relevantes parten del Impiva (Instituto para la Pequeña y Mediana Industria Valenciana) y también son relevantes las que forman parte de la iniciativa Avantic del Gobierno Valenciano. Esta última apoya la modernización tanto de la administración electrónica, como el acceso de los ciudadanos y las empresas a las tecnologías de la información ${ }^{3}$.

El portal EcSocial.com, en concreto, está patrocinado por la
Dirección General de Trabajo y Seguridad Laboral (DGTSS) de la Conselleria d'Economia, Hisenda $i$ Ocupació de la Generalitat Valenciana debido al carácter específico de las empresas que dependen del Registro de Cooperativas y Sociedades Laborales que conforman la mayor parte del llamado sector de la Economía Social.

Este tipo de empresa está reconocida por la Constitución Española. En su art. 129.2 señala que los poderes públicos deben promover la participación en las empresas, las sociedades cooperativas, y aquellas que contribuyan al acceso de los trabajadores a la propiedad y medios de producción. Sin embargo, como contrapartida, del art. $124 \mathrm{del}$ Código Mercantil se desprende que 


\section{Empresas de economía social}

Se caracterizan por su espíritu solidario, el reparto igualitario de los excedentes y la igualdad en las organizaciones (una persona un voto). Son participativas y cooperativas.

La Comisión Científica del Ciriec (Centro Internacional de Investigación e Información sobre la Economía Pública, Social y Cooperativa) definió estas entidades como ${ }^{8}$ :

"Las empresas que actúan en el mercado con la finalidad de producir, asegurar, financiar o de distribuir bienes o servicios, pero en las que la repartición de beneficios no está directamente relacionada con el capital aportado por cada miembro; y en las que las decisiones no se toman teniendo en cuenta el capital de cada socio; el peso a la hora de tomar decisiones es el mismo para todos, independientemente del capital aportado por cada uno".

En la definición aportada por Cepes (Confederación Empresarial Española de la Economía Social), aprobada en la asamblea extraordinaria de principios del 2001, economía social es entendida como?:

"Cualquier forma empresarial que integre a todas las novedades organizativas y sus correspondientes figuras jurídicas, surgidas como respuesta a las diversas necesidades que plantea la cohesión social".

A grandes rasgos, las formas jurídicas que adoptan estas empresas son: cooperativas, sociedades laborales, mutualidades, asociaciones y fundaciones.

no se encuentran obligadas a inscribirse en los Registros Mercantiles, por lo que quedan al margen de los numerosos estudios y análisis estadísticos que se llevan a cabo.

Generalmente no han integrado las TIC ni en sus procesos de trabajo ni en la comercialización de sus productos y Ecsocial.com pretende contribuir a ello.

La DGTSS ha actuado a través de la Fundación Florida.

\section{http://www.florida-uni.es}

\section{Los orígenes}

EcSocial.com es fruto de una larga trayectoria, pues sus inicios arrancan en 1999 cuando se realizó un primer proyecto: Winecs. Servicio de Información para las Pymes de la Economía Social ${ }^{5}$ http://www. winecs.com

Ese proyecto, financiado en una primera convocatoria por el Impiva y posteriormente mantenido por la Conselleria d'Economia, Hisenda i Ocupació durante los años 20002002, permitió construir la base de lo que es actualmente el Portal. En estos primeros proyectos se incidía en la información sobre la economía social, mientras que en EcSocial.com es la propia información empresarial la que ha tomado el protagonismo. Disponer de información es vital para mantener la competitividad de cualquier empresa, independientemente de su forma jurídica. Por ello, en la actualidad este enfoque es el prioritario.

La importancia de las empresas de economía social reside en la respuesta que se da desde los propios interesados al grave problema del desempleo, intentando aunar voluntades, ideas e intereses con el doble objetivo de proporcionar empleo a quienes carecen de él y al mismo tiempo generar riqueza con la creación de nuevos proyectos empresariales. Desde esta perspectiva se consideró útil crear un espacio telemático de encuentro y difusión de las posibilidades de este tipo de empresas.

En el momento en que se creó la primera versión no existía ninguna administración autonómica ni nacional que dispusiera de algo similar. En la actualidad ya son varias las autonomías que han creado portales para este sector, aunque abordando objetivos distintos al planteado en la Comunidad Valenciana $^{6}$.

\section{Beneficios para las empresas}

Hay varios factores que influyen en el uso de las tecnologías por parte de las empresas: formar a su personal, acceder a información de valía, etc.

En los inicios el principal objetivo fue mejorar el acceso a la información contable de estas empresas, especialmente de las cooperativas. Fue un objetivo ambicioso, que comportaba una labor de digitaliza- 


\section{EcSocial}

Es un proyecto promovido por la Conselleria d'Economia, Hisenda i Ocupació de la Generalitat Valenciana para el impulso de las TIC en las empresas de economía social.

Las entidades de economía social pueden consultar información económica y sectorial, un directorio de entidades (con su sector de actividad, su web, etc.), y a todas las empresas

que no disponen de web se les proporciona una herramienta que permite crearla y mantenerla de manera sencilla, e incluir todos los apartados que necesiten: catálogo de productos y servicios, noticias, eventos, promociones, etc. En EcSocial participan activamente entidades representativas y empresas del sector.

$$
\text { http://www.ecsocial.com }
$$

ción importante, pero no contó con la utilización masiva por las empresas tal y como se esperaba. El interés en tener esa información parecía proceder más del ámbito académico que del empresarial. Esto provocó un giro en los servicios a diseñar, relegándose la digitalización de las cuentas. Ahora el portal ofrece acceso integrado a una constelación de productos de información, algo que de manera aislada las empresas no podrían abordar.

\section{Servicios y su planificación}

Los servicios del portal no son especialmente novedosos, ya que muchos están ya ofertados desde otras webs empresariales. Lo nuevo es el sector de la economía al que va dirigido: la economía social, que hasta la fecha no tenía una web de referencia donde se aglutinase información de utilidad para el mismo. Las webs existentes ofrecían información aislada sobre sí mismas, cada una de las asociaciones, federaciones..., pero no estaban concebidas como un servicio de información para todas las empresas. Este es el resquicio que vino a completar el portal EcSocial.com.

Algunas de las webs semejantes estaban promovidas por federaciones, como la Federación de cooperativas agrarias, que había realizado un proyecto similar con un programa ArtePyme. Lo mismo ocurría con las Sociedades Laborales, que en esos momentos estaban en una acción a nivel nacional, a través de Confesal, para integrar a las empresas en un proyecto de comercio electrónico.

Ofrecían también un sistema de web-gestión de creación de webs de empresas con distintos niveles de acceso en función de los permisos del editor. Quizá uno de los problemas que representaban esas herramientas era no proporcionar unos pasos claros y sencillos para la creación de la web y el asesoramiento personalizado para cada una de las mismas, tal y como se expondrá para nuestro caso.

El Portal se ha estructurado en seis secciones siguiendo los siguientes criterios:
- Toda la información a mano, en un solo vistazo.

- Acceso a todo con menos de tres clicks.

\section{Secciones}

1. Directorio de entidades: Con un buscador genérico y búsquedas predeterminadas por tipo de entidad y sector al que pertenece.

2. Servicios. Trámites, ayudas y subvenciones, bolsa de trabajo, áreas temáticas, webs de economía social, ideas de negocio, y un apartado de preguntas frecuentes.

3. Recursos. Boletín de información, legislación relacionada con cooperativas y sociedades laborales, biblioteca con recursos de los principales temas empresariales.

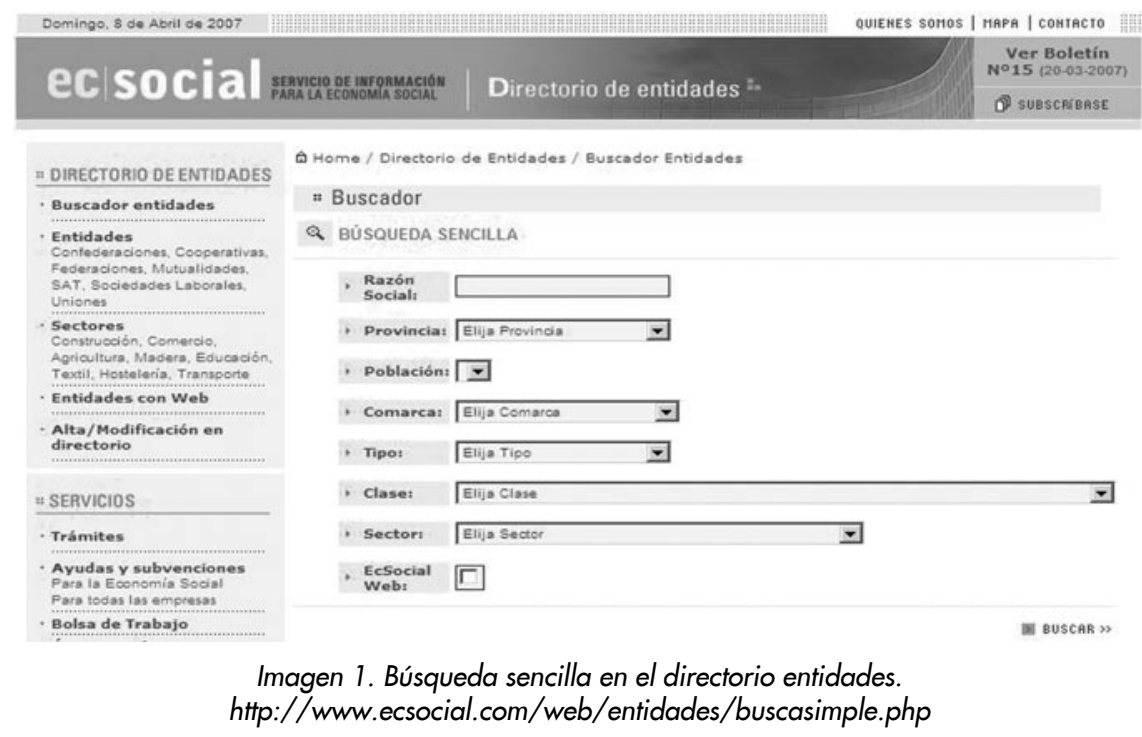


Este apartado da también acceso a otros enlaces de interés.

4. Día a día. Últimas novedades de la prensa, así como dar a conocer lo que hace este tipo de empresas y qué es noticiable. Eventos que se van a celebrar; fechas señaladas fiscales y laborales.

5. Hoy en Economía Social. Cambios realizados en zonas del portal que no se encuentran en un primer nivel, en la información que introducen las empresas en sus respectivos webs, así como la promoción de alguna de empresa concreta.

6. Web de empresa. A través de la intranet del Portal las entidades presentes en cualquiera de los registros de entidades de la economía social de la Comunidad Valencia tienen disponible un servicio de gestión de su web.

De todos estos apartados destacamos el primero, el Directorio de entidades de la Economía Social cuya fiabilidad viene reforzada porque la fuente para la actualización de la información es el Registro de Cooperativas y Sociedades Laborales. Uno de los requisitos para poder optar a las ventajas que aporta el Portal es haber realizado los trámites reglamentarios en el Registro. Son ya más de 4.000 las empresas que se encuentran en el directorio, todas ellas beneficiarias de los servicios citados. Cada ficha de empresa contiene los distintos códigos de actividad: CNAE (Código nacional de actividades económicas) y sus equivalentes en el IAE (Impuesto de actividades económicas) y la NACE (Classification of economic activities in the European Community). La ficha contiene además un campo con empresas relacionadas (datos de fundaciones, otras empresas en las que participa, etc.) tal y como muestra el ejemplo:

Uno de los servicios que mejor acogida está teniendo es la herramienta de creación de páginas web. Toda empresa inscrita en el Registro de Cooperativas y Sociedades Laborales de la Comunidad Valenciana puede disponer de los siguientes servicios:

- Dominio compuesto por: Nombreempresa.ecsocial.com.

- Todas las cuentas de correo electrónico que necesite.

- Formación y asesoramiento para crear su web.

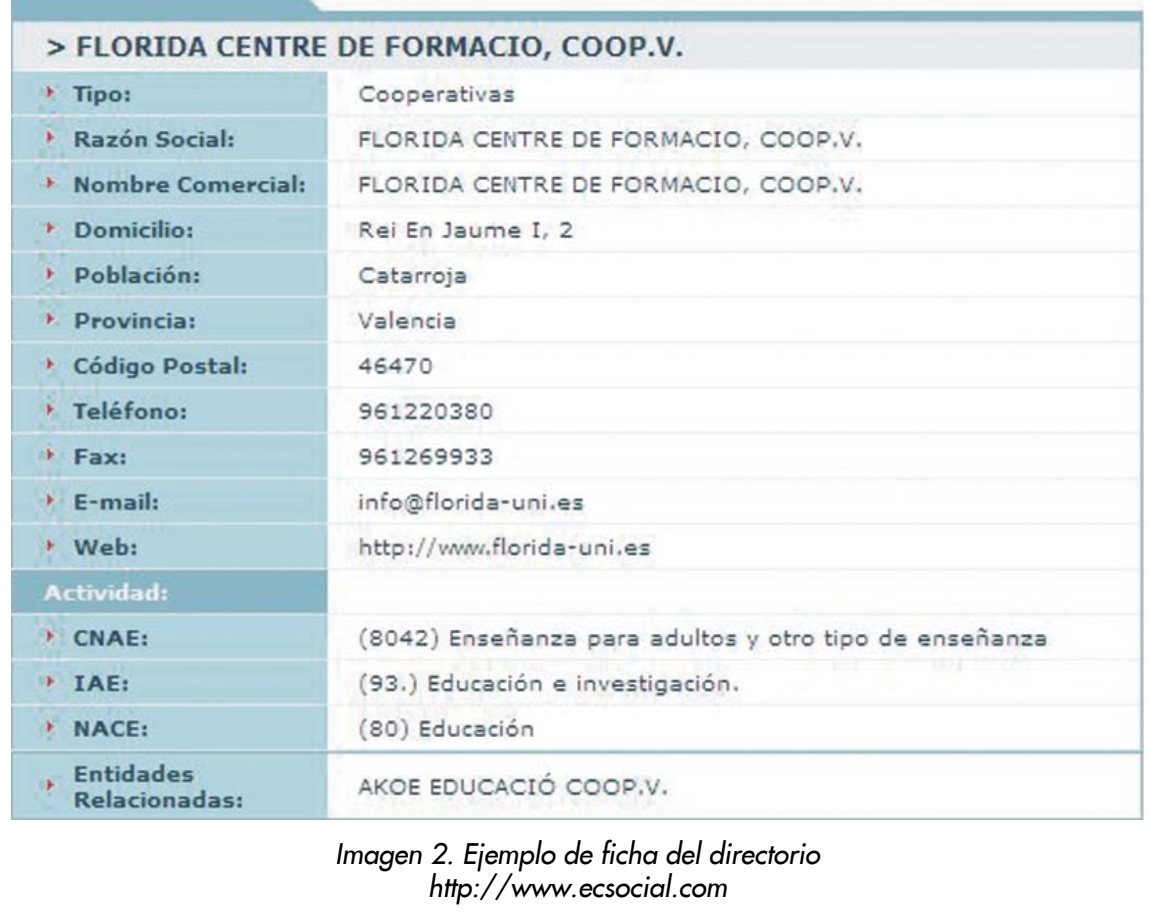

En una segunda fase se les implementará comercio electrónico.

Son ya más de 100 las empresas que superando su barrera tecnológica han construido una web; cualquier persona que sepa escribir un correo electrónico y utilizar un procesador de textos puede editar y mantener su web sin requerir ningún conocimiento especial de informática. Además, el sistema está preparado para mantener los sitios y catálogos de productos. La sencillez viene representada en esta imagen, que indica los pasos que deben seguir:

El trabajo más costoso ha sido la alfabetización tecnológica. Resulta complejo concienciar a este sector de microempresas y pymes de la necesidad de utilizar tecnologías de la información en los procesos de trabajo. Tras un estudio de implantación de las $\mathrm{TIC}^{7}$, realizado a más de 756 empresas del sector, se observó el escaso uso que los empresarios hacen de la tecnología. Para mejorar estas conductas se ha llevado a cabo un gran número de actividades de difusión, que continúan en la actualidad. Se trata básicamente de sesiones de presentación y formación. En ellas se dan a conocer a las empresas de los beneficios que les pueden reportar las herramientas del portal adaptándolo específicamente a sus necesidades en función de su cultura empresarial. Las más conscientes del incremento de negocio que les ha proporcionado su incorporación a la red son las que mayor satisfacción obtienen del proyecto (con un coste 0 ).

La mayor parte de las empresas ha podido participar gracias al apoyo de las principales organizaciones empresariales de la economía social: Confederación de Cooperativas de la Comunidad Valenciana, la Federación de Sociedades Laborales (Feves) y la Federación de Mutualidades. Todas ellas difunden el proyecto a través de sus miem- 


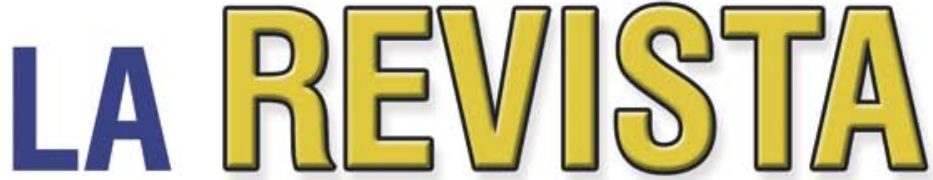 \\ DEL MUNDO DE LAS BIBLIOTECAS}

Biblioteca

秉Biblioteca.

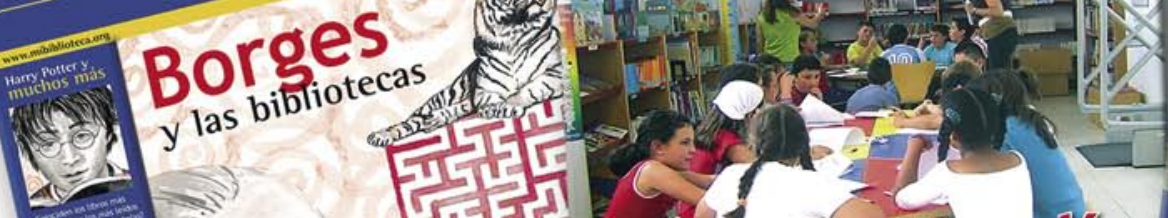

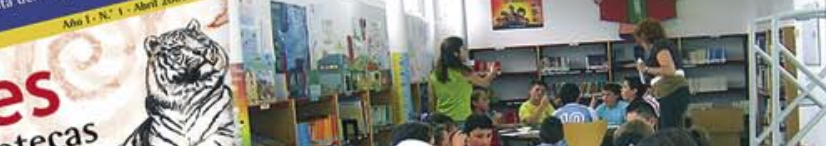

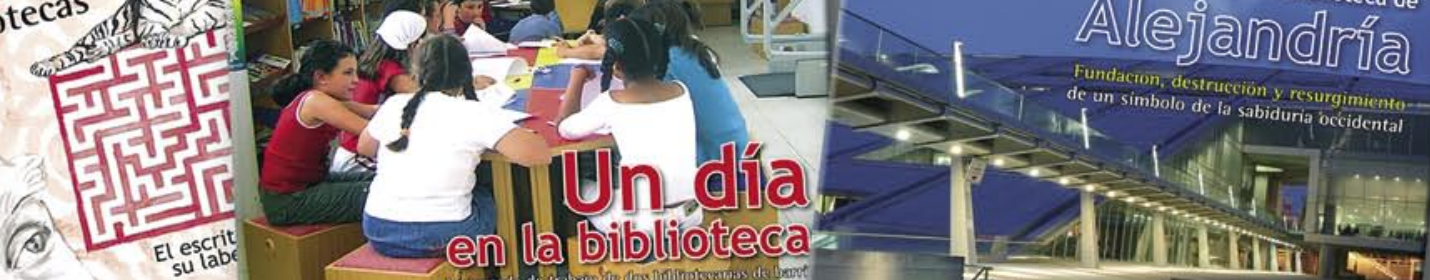
- a

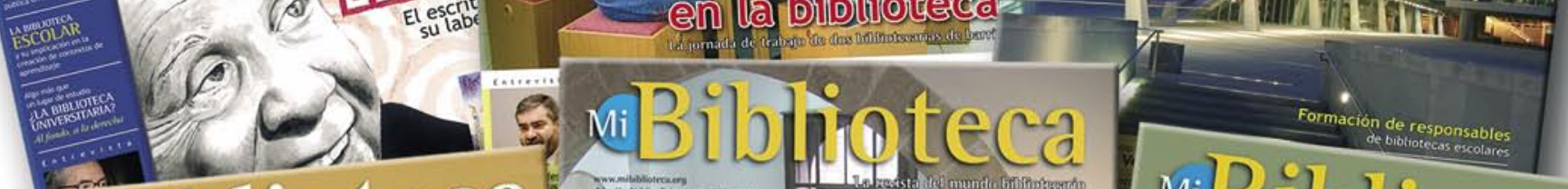
Biblioteca
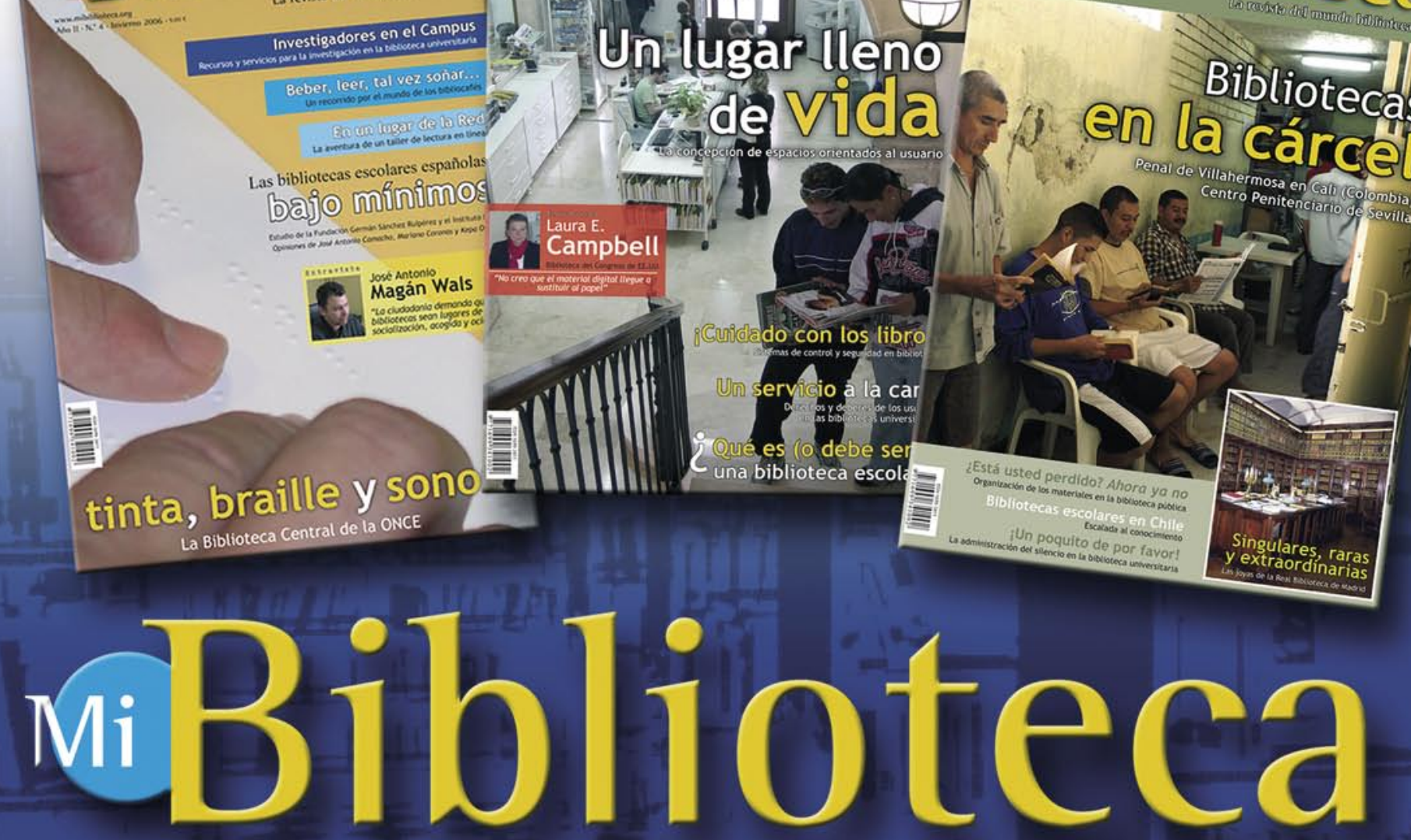

Suscríbete.

Elige uno de estos dos modos sencillos y rápidos de suscripción: por telefíono 902362869 - 952235405 a través de nuestra web www.mibiblioteca.org 

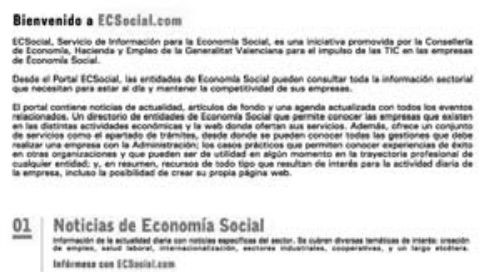

02 Directorio de entidades de Economía Social

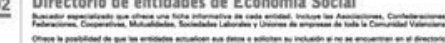
-

03 Servicios

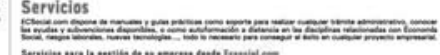

04 Recursos

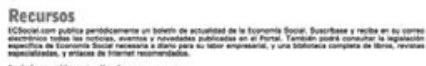

5 Agenda de eventos

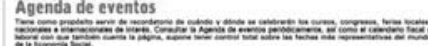

06 Cree la web de su empresa

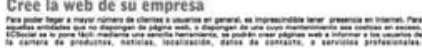
* Cómo CREAR SU WEB DE EMPRESA CON ECSOCIAL.COM

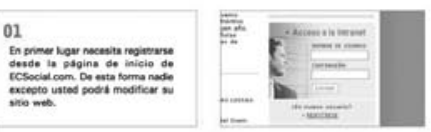

02

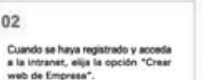

metranet tecsociat

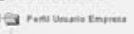

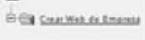

03
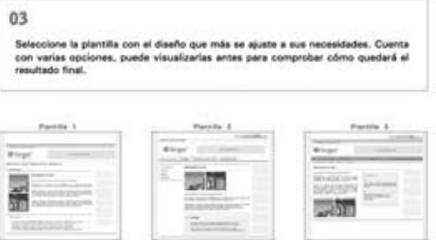
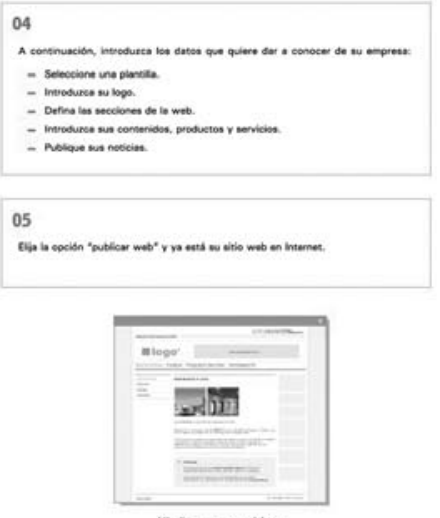

ECSOCIAL.COM su mejor herramienta de trabajo.

Imagen 3: Instrucciones de la carpeta promocional para las webs

bros y sus gabinetes de prensa nos remiten la información de carácter empresarial y económico que debe ser difundida.

Así se puede señalar que la ventaja de este proyecto ha sido acercarse al usuario y realizar unos cursos de formación personalizados. Al evitar la estandarización de los paquetes formativos, este contacto directo permite recoger sensibilidades que son traducidas con posterioridad en servicios de información de valor añadido específico. Además se ofrece asesoramiento técnico y se tratan aspectos relacionados con la arquitectura de la información, el desarrollo de contenidos, imágenes, fotografías, logotipos, etc. A su servicio se ponen expertos profesionales, en un amplio horario de cobertura, que asesoran y ayudan a las empresas a crear su web con un diseño atractivo.

Otro de los apartados de especial relevancia son las noticias. En sus inicios se nutría de las crónicas de prensa aparecidas en los medios de comunicación electrónica. Actualmente se sustenta no sólo en este tipo de materiales sino que se priorizan las que generan las empresas que integran el proyecto. El objetivo es tener un canal de difusión de todas las noticias que en otros medios no tendrían impacto. Se pretende comunicar las actividades del sector extrayéndolas de los gabinetes de prensa de las empresas, las propias webs del portal, las federaciones empresariales, etc.

El desarrollo y evolución de cada uno de los sectores se tratará más adelante.

\section{El profesional de la información}

$$
\begin{aligned}
& \text { está abierto a todos los bibliotecarios, } \\
& \text { documentalistas y otros profesionales de } \\
& \text { la información, así como a las empresas y } \\
& \text { organizaciones del sector para que puedan } \\
& \text { exponer sus noticias, productos, servicios, } \\
& \text { experiencias y opiniones. }
\end{aligned}
$$

Dirigir todas las colaboraciones para publicar a:

$$
\text { El profesional de la información }
$$

Apartado 32.280

$$
08080 \text { Barcelona }
$$

epi@elprofesionaldelainformacion.com 


\section{Planificación del proyecto}

La creación de un portal de información donde aglutinar a las empresas y conseguir impacto es una labor que debe ser planteada con un calendario amplio de actuación. Este proyecto se planeó en dos fases de un año y medio cada una, para obtener sus primeros resultados: 2004-2005 y 2005-2006.

Nuestras expectativas iniciales eran bastante optimistas en cuanto a incorporación de las TIC en las empresas, basadas en el estudio previo de necesidades del sector. Confiábamos en que una vez presentado el portal y sus servicios -correo electrónico gratuito, web de empresas, etc.-, las empresas se sumarían a la acción pues asistían de forma mayoritaria a los cursos de formación. Pero la realidad supera a la planificación. Los motivos principales para no apoyar EcSocial con sus propios contenidos eran difíciles de prever. En primer lugar, un servicio totalmente gratuito produjo desconfianza en lugar de aprecio. En segundo, la realidad de una cultura empresarial que adolecía de una falta de tradición en relación con la presencia en internet de las empresas. Cabe citar otros como la escasa formación para la redacción de contenidos para web, la carencia, en muchos casos, de elementos básicos, tales como el logo de empresa, imagen corporativa, material gráfico, etc.

Estas circunstancias fueron las que nos llevaron a planificar una reorientación de la estrategia de EcSocial. Tras un periodo de reflexión, las principales consideraciones pueden resumirse en los siguientes puntos:

\begin{tabular}{|l|l|}
\hline \multicolumn{1}{|c|}{ Actividades } & \multicolumn{1}{c|}{ Temporalización } \\
\hline Evaluación de necesidades & Enero-abril 2004 \\
\hline Diseño de la arquitectura web & Mayo-septiembre 2004 \\
\hline Diseño de metáfora creativa & Julio-septiembre 2004 \\
\hline $\begin{array}{l}\text { Implementación de la plataforma } \\
\text { informática del portal }\end{array}$ & Septiembre-diciembre 2004 \\
\hline $\begin{array}{l}\text { Herramienta de gestión de webs } \\
\text { de empresas }\end{array}$ & Diciembre 2004-marzo 2005 \\
\hline Contenidos & Octubre 2004 hasta la actualidad \\
\hline $\begin{array}{l}\text { Presentaciones en federaciones y } \\
\text { confederaciones empresariales }\end{array}$ & Enero-marzo 2005 \\
\hline Presentaciones a empresas & Abril-junio 2005 \\
\hline
\end{tabular}

Actividades realizadas en la Fase I del proyecto (2004-2005).

\begin{tabular}{|l|l|}
\hline \multicolumn{1}{|c|}{ Actividades } & \multicolumn{1}{c|}{ Temporalización } \\
\hline $\begin{array}{l}\text { Campaña de e-marketing y } \\
\text { posicionamiento }\end{array}$ & Mayo 2005-diciembre 2006 \\
\hline $\begin{array}{l}\text { Creación de herramienta e- } \\
\text { commerce para empresas }\end{array}$ & Diciembre 2005-diciembre 2006 \\
\hline Ampliación zonas del portal & $\begin{array}{l}\text { Septiembre 2005-diciembre } \\
2006\end{array}$ \\
\hline Jornada de difusión de resultados & Diciembre 2006 \\
\hline
\end{tabular}

Actividades realizadas en la Fase Il del proyecto (2005-2006).

1. Reforzar la participación de la federaciones empresariales en los procesos de comunicación con las empresas, para darles a conocer el portal y sus servicios.

2. Personalizar los cursos de formación, limitando los asistentes a un máximo 5 empresas por curso, con asistencia de dos profesionales que les aconsejan los contenidos y la imagen adecuada para su negocio.

3. Visitar cada una de las empresas con un fotógrafo profesional para mejorar su imagen gráfica.

4. Concienciarlas de la necesidad de actualizar la información de su web e incluir los productos.

Estaba claro que poner en marcha la herramienta de comercio electrónico no tenía todavía sentido si las empresas no actualizaban los catálogos de productos y precios. Se debía continuar con la actividad de formación hasta que las empresas apreciaran por ellas mismas el valor de la oferta que se les proporcionaba.

Se ha llevado a cabo una importante labor de coordinación y alineamiento de voluntades y pareceres con el objetivo de adecuar los contenidos a las necesidades de los beneficiarios potenciales del proyecto. Cabe señalar que la voluntad participativa y cordial de todas las entidades involucradas ha permitido una comunicación fluida y ágil. La cooperación entre universidadempresa-administración y entidades representativas de la economía social ha sido fundamental.

Las distintas federaciones y organizaciones empresariales han cedido sus instalaciones para poder realizar las presentaciones y sesiones de formación:

- Fundación Florida: encargada de la coordinación y desarrollo del portal, que lleva a cabo su servicio de documentación y biblioteca. Con este servicio colaboran alum- 
nos y profesores de documentación de la Universidad Politécnica de Valencia.

- Administración Pública: Conselleria d'Economia, Hisenda i Ocupació. Direcció General de Treball y Seguretat Social.

- Entidades representativas de la economía social: Confederación de Cooperativas de la Comunidad Valenciana, Federación de Mutualidades de Previsión Social de la Comunidad Valenciana, Federación de Empresas Valencianas de Economía Social (Feves), Federación de Cajas Rurales, Federación de Cooperativas Agrarias de la Comunidad Valenciana (Fecoav), Federación de Cooperativas de Trabajo Asociado (Fevecta), Federación de Cooperativas de Vivienda (Fecovi), Federación de Cooperativas Eléctricas, Federación de Cooperativas de Servicios y Transportes, Federación Cooperativas de Consumo.

\section{Colaboración de empresas}

Entre otras, han participado en la puesta en marcha y testeo de la herramienta de gestión de webs: Cooperativa Eléctrica San Francisco de Asís, Akoe, Cooperativa Agrícola de Carlet, Apuntes y suministros, Cervera Lacomba SLL, Covalex...

\section{Costes y resultados}

El desarrollo de cualquier iniciativa en la web precisa de una importante inversión, especialmente cuando su objetivo es ofrecer servicios a un importante grupo de empresas. Este proyecto, ambicioso desde sus inicios, cuenta con una importante dotación económica para llevarse a cabo en sus primeras fases. El presupuesto para la fase I alcanzó los 192.000€ y para la fase II 161.000€. Estas cantidades se han dedicado fundamentalmente a producir contenidos y a dirección del proyecto, que de manera conjunta representan aproximadamente el $25 \%$ del total.

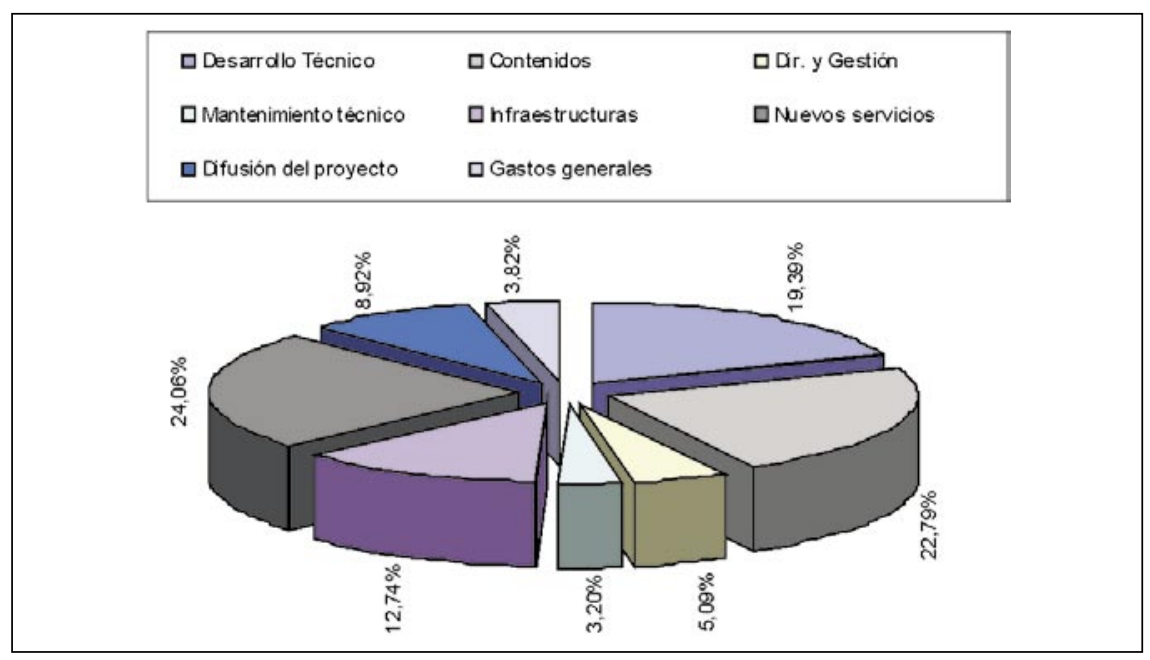

Imagen 4: Costes
En los costes de difusión y gastos generales se incluye la campaña de posicionamiento, marketing electrónico, material promocional (carpetas, folios, pendrive-USB, mailing a empresas, etc.). Actualmente la difusión se hace enmarcada en una campaña de la Conselleria dedicada a la promoción de la economía social en la Comunidad Valenciana, denominada El teu treball es el que compte. Aunque tiene su difusión a través del Portal, dispone de un presupuesto específico no ligado al proyecto.

\section{Número de empresas con web}

El número de empresas que ha participado en los cursos de formación ha sido de unas 200, con un éxito (web en marcha) de un $50 \%$ (100 webs, como se ha dicho anteriormente).

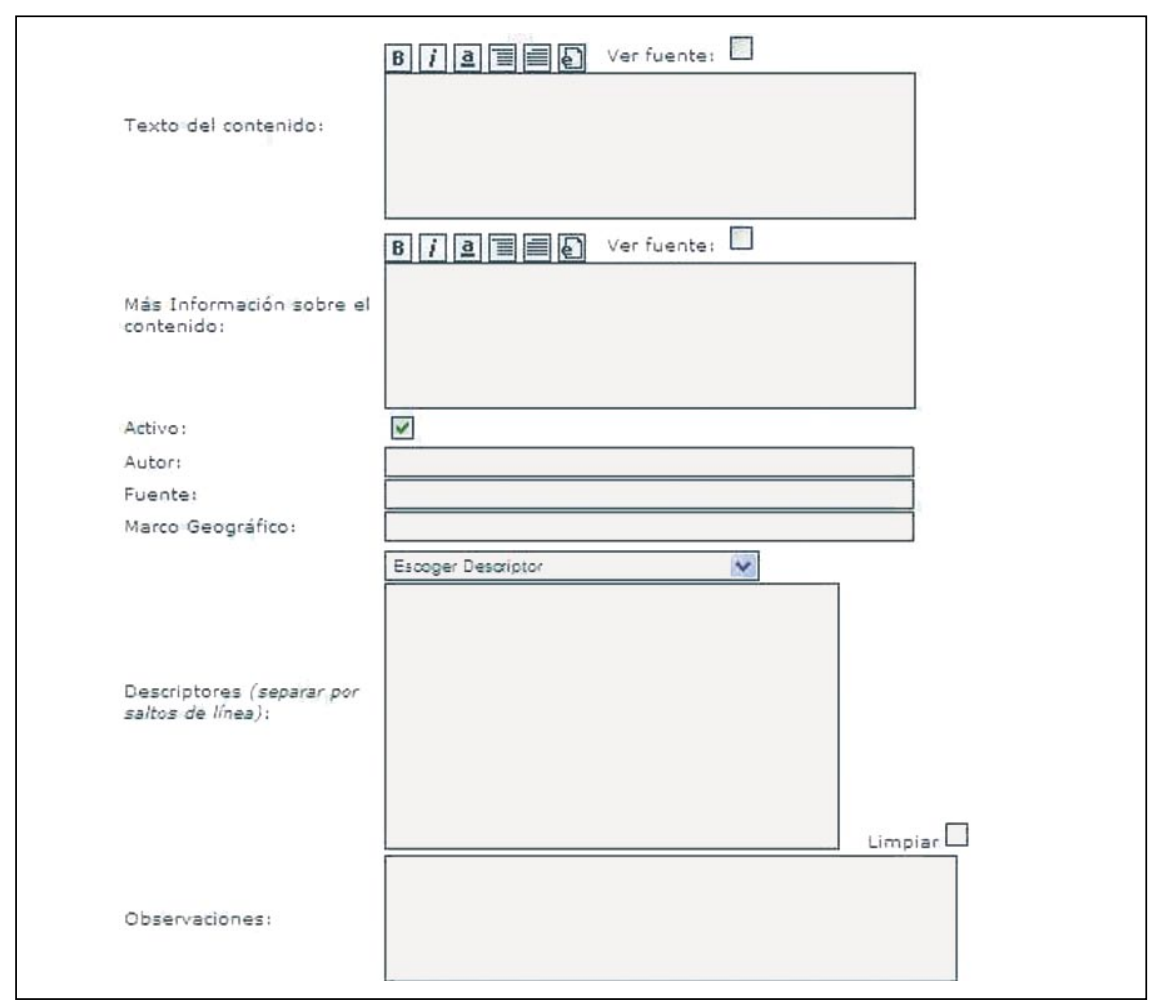

Imagen 5. Intranet del portal de EcSocial 


\section{Visitas al portal}

Se han incrementado de manera considerable después de realizar distintas estrategias de posicionamiento. Desde sus inicios la web se concibió para que tuviera un alto impacto en los buscadores. De hecho, todos los artículos y zonas del portal están relacionados mediante descriptores y enlaces. Estos descriptores generan asimismo las etiquetas meta de cada una de las páginas; esto se puede observar en la imagen de la intranet de gestión de contenidos.

De la misma manera, cuando se genera cada una de las webs de empresas se crean las etiquetas meta que las identifican.

Este trabajo no es suficiente para conseguir un posicionamiento óptimo en los buscadores por lo que se ha trabajado en estrategias propias para mejorar la posición. De entre todas ellas los mejores resultados se han conseguido tras elaborar los mapas oportunos de cada una de las webs.
Ha sido durante 2006 cuando este servicio ha tenido un mayor impulso, siendo un indicador del éxito de EcSocial el que el número de visitas a las webs de las empresas haya superado a las del portal propiamente dicho.

\section{Cursos de formación impar- tidos}

La creación de webs a través de los cursos de formación ha sido mayoritaria, aunque luego hayan recibido apoyo para finalizarla. Los webs tutorizados, es decir, los que han sido hechos mediante visita a la sede de Florida para crearla individualmente, han sido los menos.

\section{Correo electrónico}

Ha tenido escaso éxito. Únicamente son 19 las entidades que se han acogido a este servicio. Los motivos son variados: la mayoría de las empresas ya usaban un correo electrónico de los servicios gratuitos Gmail, Yahoo, etc., todos ellos disponibles por webmail, cuando el de EcSocial debía instalarse con un cliente, cuyo uso parece no estar ex- tendido entre los usuarios con escasa formación en internet. Además, para muchos tiene el inconveniente de únicamente poderlo consultar cuando se encuentran en su lugar de trabajo.

Actualmente se está trabajando en el desarrollo de un webmail para poder ofertar a las empresas este servicio, pues se considera importante de cara a la imagen de la empresa que la dirección web y la del correo pertenezcan al mismo dominio.

\section{Contenidos}

Ha incorporado más de 4.453 noticias relacionadas con el sector. La página principal ha sido la parte más dinámica, actualizándose los siete días de la semana a lo largo de todo el año. El resto de secciones se ha actualizado semanalmente, excepto la de trámites y legislación. El boletín electrónico ha tenido una publicación bastante irregular, no llegando a la constante quincenal que se había establecido inicialmente.

\section{Emerald - ¡40 años en el mundo editorial!}

Visítenos en FESABID 2007, en el stand n 62 y únase a la celebración.

\section{@EmeraldManagementXtra}

Emerald Management Xtra, la base de datos de dirección en línea fundamental, fue creada después de haber llegado a comprender en profundidad las presiones y necesidades reales a las que se enfrentaban las escuelas de empresariales, universidades y profesionales de la información de todo el mundo.

Emerald Management Xtra se compone de:

- 150 publicaciones que contienen 65.000 artículos completos con una amplia variedad temática, entre las que se incluyen áreas como la Biblioteconomía y Documentación, y la Información y Gestión del Conocimiento.

- The Librarian Toolkit - diseñado para ofrecer a los bibliotecarios ayuda, formación y soporte con el objetivo de maximizar el uso de los productos de Emerald.

- Una licencia global de la institución que permite a los usuarios acceso sin restricciones a la base de datos en línea, tanto en e campus como fuera del mismo.

\section{PERÍODO DE PRUEBA GRATUITO de 40 dias}

Para celebrar el 40 aniversario de Emerald, nos complacemos en ofrecer a su institución un período de prueba gratuito ampliado a 40 días de Emerald Management $X$ tra. De este modo, toda su institución podrá tener acceso a publicaciones en línea profesionales y teóricas de gran calidad.

Para obtener esta prueba gratuita de 40 días de Emerald Management $\mathrm{X}$ tra, visítenos en FESABID, en el stand $\mathrm{n}$ \% 62 o envie un correo electrónico a emerald@emeraldinsight.com indicando"FESABID"

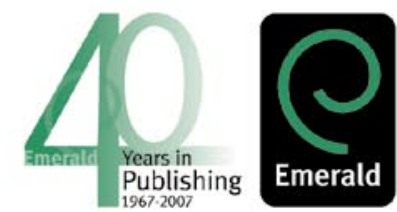


Mejora y consolidación de imagen de las empresas participantes

La imagen que proyecta una empresa a través de su web es fundamental para sus negocios. Esta máxima no es ajena al sector de la Economía Social. Una vez vista la proyección de nuestras empresas a través de sus webs se consideró un buen servicio ofrecerles una sesión fotográfica realizada por un profesional. La acogida fue espectacular. En los últimos meses se visitaron setenta empresas a las que se hicieron fotos de su producción, talleres, locales, etc.

Estas visitas han contribuido a mejorar la imagen de las empresas, a las que se les han remitido también las fotos para que puedan utilizarlas para cualquier tipo de promoción de sus productos.

Una vez dado este primer paso, las empresas se han preocupado de la imagen proyectada y han recurrido al servicio de atención online (teléfono y correo electrónico) para mejorar el aspecto inicial. Por ello, y por el incremento de nuevas webs, el número de horas de asistencia ha llegado a alcanzar una media de 30 semanales.

\section{Conclusiones}

Tras la puesta en marcha del proyecto y tras un trabajo continuado a lo largo de varios años hemos podido constatar aspectos que, a nuestro entender, no se recogen en los estudios sobre tecnología para empresas que se han elaborado hasta la fecha. La mayoría de los trabajos se dirigen a las empresas de mediano tamaño, pero no tienen en cuenta a las microempresas, que son mayoritarias en el sector que tratamos. Este tipo de empresas, aunque conocen internet y la web, no la relacionan con un impacto directo en sus negocios. Son minoritarios los casos en los que sí habían apreciado una clara conciencia y la posibilidad de visibilidad y negocio en esta plataforma.

Por otro lado, en muchos análisis el énfasis del crecimiento relaciona la implantación de tecnología con una mejora real. Nuestro proyecto demuestra que la participación de este sector empresarial en la sociedad en red no es una cuestión tecnológica. El incremento de cultura empresarial con más amplias miras y la formación de las personas son aspectos mucho más necesarios para que aumente la presencia en la Web que la pura oferta tecnológica.

Nuestra experiencia, además, nos ha demostrado que la entrega de productos totalmente gratuitos genera desconfianza. En lugar de ser una ventaja suele ser un inconveniente, en algunos casos, para la promoción de los servicios. Las empresas no creen que algo gratuito pueda responder a largo plazo, y consideran que en algún momento se les va a pedir el abono de cantidades por una cosa que no han tenido la opción de elegir.

Por otro lado tienen reticencias para incorporar los precios de sus productos en su web; lo ven más como una desventaja que como una ventaja. La competencia puede copiar sus precios u ofertar productos de manera más competitiva. Para generar confianza ha sido vital el papel de las federaciones empresariales y la administración pública.

En resumen, las principales propuestas de mejora y desarrollo van dirigidas a incrementar la conciencia para la actualización de los webs, actualizar el catálogo y precio de los productos y testear el nivel de uso que puedan hacer las empresas de una herramienta de comercio electrónico.

También, y después de un análisis de los logs de visitas, se va a cambiar el peso de algunas secciones. Las que reciben un mayor número de visitas son el directorio de empresas y el listado de webs. Las noticias, aunque consultadas, únicamente tienen impacto las que se encuentran en un primer nivel en la home, siendo mucho menos leídas las de segundo y tercer nivel. Por el contrario, algunos de los documentos a texto completo del área de formación y de seguridad y salud tienen una acogida considerable, por lo que se estudiará la posibilidad de aumentar su número.

\section{Notas}

1. World Academic Forum. Global information technology report 2004-2005. Consultado en: 10-01-2007.

http://www.weforum.org/pdf/Global_Competitiveness_Reports/Reports/GITR_2004_2005/Networked_Readiness_Index_Rankings.pdf

2. World Academic Forum. The networked readiness index ranking 2005. Consultado en: 10-012007.

http://www.weforum.org/pdf/Global_Competitiveness_Reports/Reports/gitr_2006/rankings.pdf

\section{Programa Avantic.}

http://www.avantic.es/

4. Constitución española. Madrid: Congreso de los diputados, 1999. Consultado en: 28-05-2006. http://www.congreso.es/funciones/constitucion/ titulo_7.htm

5. Ferrer, Antonia. "Winecs 2001. Una experiencia en la digitalización en el registro de Cooperativas de la Comunidad Valenciana. V Jornadas de archivos electrónicos. Priego (Córdoba): Ayuntamiento, 2002

6. Cabe destacar el portal creado por la Confederación de Cooperativas de Galicia, el Portal de Economía Social de Andalucía, o el de la Generalitat de Catalunya.

http://www.cooperativasdegalicia.com/ http://www.gencat.cat/treballiindustria/ambits/ economia_social/index.html

7. Ferrer, Antonia; Sanz-Blas, Silvia; Ontalbay-Ruipérez, José-Antonio; Peset, Fernanda. Las TIC en las empresas de Economía Social de la Comunidad Valenciana. Estudio descriptivo. Catarroja: Florida Edicions, 2006. pag. 97-100. Consultado en: 8-01-2007.

http://www.ecsocial.com/web/docs/estudio_tic. $p d f$

8. Barea, José. "Concepto y agentes de la economía social". Ciriec-España. En: Revista de debate de economía pública, social y cooperativa, 1990, n. 8, oct., pp. 110-115.

9. Cepes. Economía Social. Modalidades. Madrid: Cepes. Consultado en: 8-04-2007.

http://www.cepes.es/sumseccion3_2.cfm? iddisciplina $=2$

10. Vidal, Isabel. "La economía social en España”. En: Ciriec-España. Revista de debate sobre economía pública, social y cooperativa, 1990, n. 8 , octubre, p. 29 